\title{
PSYCHOLOGY AND CULTURE
}

\section{Rudimentary functions: Important reminders of history and relationship}

\author{
Natalia Y. Collings \\ Department of Teacher Education and Professional Development, \\ Central Michigan University, U.S.A.
}

Corresponding author. E-mail: colli1ny@cmich.edu

Background. When Vygotsky suggested the term rudimentary functions for psychological phenomena, he drew a parallel with organismic rudiments that existed and continue to exist in a number of biological species. These rudiments used to play an important role in the life of an organism and allow us to study that life in the process of its development. Vygotsky originally gave three explicit examples of psychological rudimentary functions: 1) attributing an important decision to the result of a solitaire card game, 2) tying a knot in a handkerchief in order to remember and do something later, and 3) counting on one's fingers.

Objective. The purpose of this article is to offer a contemporary overview and paths for development of L.S. Vygotsky's notion of rudimentary function.

Design. This paper, in the genre of a theoretical article, drew on existing research and theoretical literature to advance a theory. I analyzed Vygotsky's original example of a solitaire game and similar actions (for example, flipping a coin), arguing that these actions represent key events mediating choice and exercising human will over affect. I then focused on three more psychological functions that fit Vygotsky's definition of rudiments: 1) photographic memory and déjà $v u$ as instances of historically primitive eidetic memory, 2) talking to oneself aloud as a rudiment of a key event forming the self-regulatory mechanism of inner speech in childhood, and 3) fantasizing, which could remind us of our young age, when imagination readily created what was lacking in external world.

Results. This analysis allowed me to vividly illustrate the historical and relational focus of Vygotsky's theories.

Conclusions. Rudimentary functions, often perceived as mysterious, in their simplicity can be powerful reminders that historically primitive functions do not disappear, but enter complex relationships with other psychological functions, and that many relationships are possible within different cultural-historical formations, with Western civilization being just one example.

Keywords: Cultural-historical theory, higher and lower-order psychological functions, double stimulation 


\section{Introduction}

Have you ever flipped a coin when unable to make a choice or drawn a cross on your palm in order to remember to do something later? If so, have you also thought about the significance of these actions, or compared them to the vestigial appendix in your lower right abdomen?

This manuscript is dedicated to creating a contemporary, comprehensive overview and, most importantly, to the development of Vygotsky's ideas related to rudimentary functions. The most focused analysis of these ideas was given by that author in his essay "Istoriya razvitiya vysshikh psikhicheskikh funktsii" ["The history of development of higher-order psychological functions"] written in 1931 and published in volume 3 of his collected works in 1983. He wrote: "Rudimentary functions, in the same way as organs, are documents of development, living witnesses of old epochs..." (Vygotsky, 1983). Vygotsky (1983) made it clear that the point of studying rudimentary functions was to find an answer to the question of what is developing and also to establish a historical (or, as he also called it, genetic) method of studying human psychological development overall.

The answer to the question of what is developing can be posed as the process of mediation of human response to the environment. In a dialogue with writings by Russian physiologist Ivan Pavlov (on the development of conditioned stimuli), Vygotsky proposed a simple understanding of the difference between the conditioned stimulus and the process of human mediation: the former remains largely unchanged within the species, while the latter develops historically, thus proclaiming the fundamental superiority of human species. Vygotsky stated that rudimentary functions are "symptoms, evidence" (1983) of this historical development.

Rudimentary functions deserve close attention for several reasons. First, a contemporary exploration of rudimentary functions can become a vivid reminder of the historical nature of human development as a key Vygotskian idea. It can deepen the attribution of a Vygotskian essence to such models as sociocultural theory and social constructivism. These theoretical models in themselves lack a genetic and cultural-historical focus. I first determined the need for such a reminder when teaching educational psychology in the United States. I felt that the textbooks often lead pre- and in-service teachers to believe that Vygotsky wanted them 1) to organize days of international food tasting as an application of his sociocultural theory, and 2) to encourage group work in order to enact his Vygotskian social constructivism. I found that Vygotskian thought was given much more credit when we discussed with the students of pedagogy how, for example, the child's seemingly immature response to a problem could be a reflection of an important psychological development of the human species far back in history. We concluded that when a young child randomly picks an answer on a bubble sheet, the teacher could think of this as a remnant of the first time that a man threw dice in order to make a choice, taking control of a situation (instead of thinking of the child's action as careless guessing).

Another reason to revisit the idea of rudimentary functions is their importance for advancing the field of developmental psychology. According to $\mathrm{Vy}$ gotsky, psychological rudiments in adults correspond to what we observe in the process of child development (1983). Using the terms phylogenesis to describe the development of the human species, and ontogenesis to describe the individual 
development of a child, Vygotsky endorsed the idea that ontogenesis recapitulates phylogenesis in a complex and significant way. As Vygotsky's student Vasily V. Davydov wrote (1980), understanding the relationship between the historical laws that shape practical and theoretical human activity in phylogenesis and the activity of a child that reproduces culturally and historically formed abilities, is critically important for advancing the cultural-historical, dialectical theory of human development.

The goal of calling attention to rudimentary functions is to explore what becomes "fossilized" in these functions, and what they are capable of reminding us about when they surface in our everyday lives. "They are monuments of the greatest attainments of culture, dragging out a pitiful existence in an epoch that is foreign to them. If anyone wanted to discover the history of each rudimentary form, he would see it on one of the great historical roads of humankind. If we were to discover it ethnologically, we would see a universal stage of culture, to which all peoples rose at different epochs and in a different form" (1983). The holistic nature of what becomes a rudimentary function (e.g., flipping a coin to make a choice) helped Vygotsky to achieve the revelation (which he first articulated in a presentation made in 1930) that lower-order functions are not simply transformed into higher-order ones, losing their identity, but enter new relationships with other psychological functions (Vygotsky, 1982, vol. 1). Initially collective functions do not stop being social when they become internalized. This reminds us of the primacy of our collective nature and the essence of relationship in our lives. Inspired by this powerful reminder, my hope in this paper is to create, using Vygotskian language, new Zones of Proximal Development (ZPDs) for understanding the meaning of rudimentary functions, and consequently to create new ZPDs in our everyday development and interactions.

\section{Method}

This paper, in the genre of a theoretical article, drew on existing research and theoretical literature to advance a theory. It was guided by the initial question, "How can the classic cultural-historical concept of a rudimentary function help create new understandings of human development?" Multiple sources were revisited and newly located in a search for most relevant concepts, which were then organized in four parts, each investigating one of the rudimentary functions (flipping a coin, eidetic memory, self-talk, and fantasy).

\section{Results}

\section{Flipping a Coin}

The human ability to use auxiliary stimuli in order to mediate a choice was central to Vygotsky's exploration of rudimentary functions. He gave the example of Pierre Bezukhov from Lev Tolstoy's "War and Piece" using a game of solitaire when deciding whether he should remain in Moscow or join the army. Another common form of this rudimentary action is flipping a coin. Playing a card game or flipping a coin have no relevance to making important choices, but they are ways to bring a situation of choice under control, which is something that historically distinguishes a 
human being from the rest of the animal world. To illustrate this idea, Vygotsky described the philosophical problem with a donkey (attributed to the medieval philosopher Buridan), where the animal died when placed at an equal distance from two equal heaps of hay. The story was that the donkey (now famously known as "Buridan's ass") could not choose between two competing stimuli, whereas a man would take control over nature, at the same time changing his own nature once and forever. Unlike Buridan's ass, a primitive man, when faced with a difficult choice or decision, could throw dice or wait to see a dream about the decision that needed to be made (Vygotsky, 1983). Vygotsky further supported the idea of animals' inability to choose, as in the case of the fictitious Buridan's ass, with actual experiments performed by Pavlov on dogs and by several psychologists on chickens. Pavlov's dogs did not have the expected responses when presented with competing stimuli; moreover, they became mentally disturbed. The chickens were trained to always peck from a lighter surface, and then were presented with surfaces the tones of which they could not differentiate. Unable to choose from which surface to peck, the chickens died - not from hunger, as in the case of Buridan's ass, but from intensity of affect.

Being able to mediate choice is an activity of auto-stimulation that goes beyond external stimuli, i.e., immediate options presented for a choice. The higher-order psychological function of auto-stimulation establishes control over affect through categories of cognition and volition. For Vygotsky, this is one of the key moments in the historical development of human activity, closely connected to his readings of Baruch Spinoza (Derry, 2013). In the process of its phylogenesis, civilized society has developed many ways to mediate natural, primitive reactions. Vygotsky focused on finding the root of mediation, the unmediated unit, and this unit could be expressed in a dialectical opposition of affect and volition.

As was proposed in a hypothesis of complex interconnectedness of phylogenesis and ontogenesis by Vygotsky and emphasized by Davydov (1980), children also begin with primitive, impulsive responses guided by affect alone and gradually learn to mediate them in... play. If we think again about the rudimentary functions that fossilized the first instances of mediating choice, we find that they are elements of a game: Throwing a coin is akin to throwing dice in a board game, while playing solitaire is just that - playing a game. As was thoroughly and passionately investigated by Vygotsky's colleague Daniil B. El'konin (El'konin, 1978), play historically is an adult activity reflected in the rituals of primitive peoples - for example, in the rituals that surrounded hunting. Playing, or performing, a successful hunt was a way to take control over an actual collective event. The elements of adult play remained not only as rudiments: They fully exist, for example, in team sports and gambling. For another example, games that help build effective collective work are popular for the purposes of personnel training (Williams-Bell et al., 2015; Chittaro, 2015).

Play is fully understood when one realizes that its core unit is a role and that what is played is always a social relationship (El'konin, 1978). Children begin to role play relationships in the cultural-historical formations that Marx so famously characterized by division of labor. When labor becomes divided, children can no longer fully participate in the practices of their community as true apprentices, and start learning professional and family relationships by playing them. Children's 
play in the bourgeois middle-class world reproduces most important features of concrete social relationships, making them abstract. Abstraction in itself is an important cognitive tool of taking control. It is important to understand that children take control not over the relationships themselves, but over the historical capital of the human species, following, in the words of Marx, its familial nature and at the same time creating it.

A Vygotskian understanding of initial affect can be a powerful humanistic tool in dealing with young children's outbursts. It helps us remember that children's emotions are never meant to upset anyone. Encouraging play remains the most historically relevant activity in helping children establish their will, first over their interactions with another person, and ultimately over oneself (Lobman \& Katelyn, 2015; Perone, 2014). Contemporary Vygotskians also propose that play is equally relevant to the development of adults (Holzman \& Newman, 2013). The unique power of human beings to create auxiliary stimuli in mediating choice between immediate stimuli, according to Fred Newman and Lois Holzman, can and should continue to be used by adults in creating new emotions in their relationships with others, instead of seeing them as personal attributes created by the past and affecting their present and future (Lobman \& O'Neill, 2011). Holzman, after the death of Newman, has endured a battle against clinical labels such as depression and ADHD, offering an alternative of gathering people for playful performances of their better selves (Holzman, 2015 and 2016).

\section{Eidetic Memory}

When I was a student in high school and university, I sometimes had an ability to look through the pages I needed to study and "photograph" them in my memory. When asked to retell the information, I could visualize the photographed pages and mentally "read" them while standing in front of the teacher and my peers. Years later, I read an explanation of this phenomenon given by Vygotsky's colleague Alexander R. Luria: "The essence of this form of memory is in that person is able to see, literally, the object that was shown once right after viewing it, or even after a long period of time. Such persons and the form of this memory are called eidetic" (Vygotsky \& Luria, 1993).

Vygotsky and his colleagues explain that the cornerstone of historical development of human memory is in its shift from reproductive remembering to creative ponderings. Until human beings in the history of their development begin to mediate their memory by symbols, unmediated memory is stunningly vast. It is also associative in nature, making connections among what is remembered based on mostly sensory experiences. This feature of historically primitive memory may also explain another phenomenon that seems to readily fit the definition of a rudimentary function: déjà $v u$ (French, "already seen"). In cases of déjà $v u$, when we have a feeling that what is happening has happened before, but we cannot recall when and how, the memory presents itself as an image, as a text saved in a file format that does not allow us to perform a word search or edit a specific sentence.

Reproductive memory and imagination are two unmediated psychological functions that are most vivid and often studied in children, both by Vygotskians and many other psychologists. Vygotskians, and Alexey N. Leontiev in particu- 
lar (Leontiev, 1959), in their investigations of memory in preschool children and unschooled populations, arrived at the conclusion that both initially remembered large amounts of information verbatim and did not rely on symbols offered by the experimenters to organize information. At the time of the child's first school experiences, both groups of subjects began to increasingly remember more with the help of external signs offered by the experimenter. As formal learning accumulated, the presence of external symbols on notecards stopped making a significant difference in the amounts of remembered information. Educated children and adults had internalized mediation/signification and now organized their memories without the need of physical artifacts. Leontiev discovered that remembering with and without notecards formed two lines that initially grew apart and then flowed towards each other. He graphically portrayed this discovery in what is known as "the parallelogram of development," where the use of notecards represented the upper line and internal remembering depicted a lower line (Vygotsky, 1983; Vygotsky, 1984).

Neurology and special education are examples of two prominent fields that pay attention to lower-order capacities of memory, which are often also approached in the study of savants. Historically and rudimentarily possible synthesis of perception and cognition, which also happens in atypical development, is fascinating and full of potential. Imaginative thinking is a successful pedagogical and psychological method (Miranda, 2015; Herkert \& Miller, 2015). Most arts are inconceivable without imagery. I am certainly not an eidetic person - photographic memory and déjà $v u$ rarely surface in my life - and I seem to have little control over them, as seems to be the case with most rudimentary functions for most people. Thinking about them as rudimentary functions in the Vygotskian sense, however (rather than random, inexplicable occurrences), helps establish the familial nature of the human species and to take control over rudimentary functions in a dialectically scientific way.

While eidetic memory and déjà $v u$ are rare rudiments of unmediated forms of memory, the first instances of signification also became crystalized, illustrating the history of development of human memory. Vygotsky describes them as out-of-date instances of tying a knot in one's handkerchief in order to remember to do something later. Now handkerchiefs are rarely used, and not everyone will recognize this action, but I remember my great-grandmother doing it with a little hankie that she carried in her pocket. The same rudimentary function got preserved in English language as an idiom "tie a string around your finger". Today we may more frequently observe a person drawing a cross on his or her palm, which has the same function as a knot or a string. Even more frequently, we see the use of mnemonic devices in education, such as "Please Excuse My Dear Aunt Sally" (PEMDAS: parentheses, exponents, multiplication, division, addition, subtraction); the acronym is intended to help students remember the order of these mathematical operations. No matter what the form is, these rudimentary actions remind us of the first uses of auxiliary symbols in mediating one's perception, turning it into purposeful memories. It is important to mention that the activity of tying knots was also a form of primitive writing, thus connecting it to memory in a very important historical context of development. "The first knot tied to remember, signified the birth of written speech, without which civilization wouldn't be possible" (Vygotsky, 1983). 


\section{Self-Talk}

I decided to begin this section with a vignette of a situation that initially inspired my decision to write about rudimentary functions. One day I walked into the printer room at work and saw my colleague Norma there. "OK," she was saying, "open the upper drawer, make sure the paper is not jammed, then lift the handle on the left, check underneath..." At that point she noticed me and declared: "I talk to myself." Then she scratched her gray-haired head and continued verbally guiding herself through solving the mystery of the printer not printing when needed the most.

Norma's talking to herself is probably one of the easiest examples of rudimentary functions to understand. When she "talked to herself" at the age of five, she never announced this to the audience as something out of the ordinary. By the time her hair had turned gray, self-talk had become a rudiment that is as familiar and mysterious to us as the timing and conditions of printer breakdowns. Norma fixed the printer. Will I be able to help shed more light on what role talking to herself played in this success story?

This is going to be more complex than in the cases of flipping a coin and eidetic memory, mostly because it is not as easy to point to the historical equivalent of self-talk in phylogenesis. In the works of Vygotsky and his colleagues, one can find many instances of genetic analysis proving the absence of speech in chimpanzees and the presence of egocentric speech in young children, but no proof of primitive people talking to themselves out loud. It is the absence of an obvious counterpart that I will use as a path in this journey.

The lack of a direct historical parallel to self-talk, first and foremost, may be used to point at a difference in the genetic roots of speech and thought that was at the core of Vygotskian investigation. In an argument with many other psychologists of his time, Vygotsky repeatedly pointed out that inner speech (which also can be referred to as verbal intellect, or mental discourse, from the Russian rechevoe myshlenie) is not thought by itself and only represents a small part of it: "The relationship between speech and thought can be illustrated by two intercepting spheres that would show that part of the processes coincides in the area of verbal intellect. But verbal intellect comprises neither all forms of thought, nor all forms of speech" (Vygotsky, 1982, vol. 2). For Vygotsky it was important to remind us that a large part of our thinking is non-verbal and governed by laws of practical (technical, instrumental) intellect that we share with the rest of the animal kingdom. It is verbal intellect and speech, however, that made the human species unique and superior on the path of development. "The word, itself intellectually developing on the basis of action, puts the action on a higher step, ... puts a stamp of will on the action.... [I]f at the beginning of the development there was action, independent of the word, then at the end of it stands the word that becomes a deed. The word that makes human action free" (Vygotsky, 1984). Thus, self-talk can remind us that verbal thought both distinguishes humankind and doesn't let it forget about its closeness to nature, because it neighbors with practical intellect that is shared across the species.

The inability to readily find a primitive ancestor of self-talk can also illustrate the complexity of change in relationships among psychological functions at various stages of historical development. The main function of self-talk is in creatively 
planning an action. We certainly find many instances of such creative planning in primitive societies, for example in the ritual performance of a future hunt, as discussed above. The rituals were not primarily verbal, but clearly had the principal function of planning rather than communicating. Given the difference in the genetic roots of speech and thinking, they can be understood as early instances of the speech category and even as the historical counterpart of self-talk that seems to be missing. In this case it would be not speaking, but another activity that historically entered new relationships to what later became inner speech.

Vygotsky and his colleagues emphasized the study of self-talk in children, in which context they often called it egocentric speech, borrowing the term of Jean Piaget. Even if we can't find the ancient precursor of self-talk, when adults speak aloud to themselves, they reveal a rudiment of an important organ that used to be fully functioning in their childhood. Piaget approached egocentric speech as the most cognitively limited stage in language development, gradually purged by speech directed to the other, as the brain grows and gains capacity to consistently accept that other's point of reference. Piaget considered egocentric speech as different from social speech and described them co-existing for some time during the process of child development. From the cultural-historical perspective, children's speech, just like the speech of Neanderthals, is initially purely social, with a primary function of communicating something to someone. Egocentric speech develops when the leading function becomes that of planning an action, of taking control of one's behavior. Vygotsky admitted that egocentric speech in its structure is simpler than social speech, but only to support the overall principle that he proposed: "When complex social forms of cooperation enter the sphere of individual behavior, they begin to function according to the laws of the primitive whole, part of which they now embody.... The transition from the collective form to the individual one initially lowers the level of the whole operation.... [E]gocentric speech in its structure is lower than regular speech, but as a stage of development it is higher than the social speech of a child of the same age" (Vygotsky, 1984). Thus talking out loud to oneself, in both children and adults, is an important reminder of the social, cooperative origin of all psychological functions, and of the initial simplification in the process of their internalization.

Just as in the case of play, many fields and disciplines have explored self-talk for its rich potential. For example, it has been proposed as a powerful tool for increasing athletic performance (Blanchfield et al., 2014; Cutton \& Hearon, 2014; Zourbanos, 2013), establishing psychological well-being (Kross et al., 2014; Wiley, 2016), and leadership training (Regelberg et al., 2013).

\section{Fantasy}

Here I take a risk of sharing an even more personal account of understanding the importance and continued existence of rudimentary psychological functions in their new, higher-order cultural and historical relationships. It came from my experience with a play, "Carmen's Place (A Fantasy)," by Fred Newman (1998), a contemporary Vygotskian scholar, author, and activist who was introduced earlier in this article. The main character in the play is a waitress named Carmen who has a boyfriend named José, who is a police officer. They are both typical working-class 
New Yorkers, second generation immigrants from Puerto Rico. They are special in knowing that to love means to give, and not to possess. Carmen is not ready to make a commitment to marriage, feeling a void, a need to experience something new. This new thing becomes a possessive love by Placido, an opera singer who happens to perform the role of the toreador Escamillo at the time of their relationship. Unlike Carmen from the famous opera by Bizet (based on a novel by Merimée), Newman's character does not get destroyed by the affair and does not betray José. In Carmen's words, an experience with passionate romanticism creates a space for herself, a space where she can fantasize.

Fantasy and dreaming are two more psychological functions that seems rudimentary in the contemporary Western cultural-historical formation. "It is rather different in case of a small child. Not capable of organized actions, they take the path of minimal resistance: If the external world doesn't give them something in reality, they compensate for it in fantasy. Incapable of reacting appropriately to delay in fulfilling their needs, they react inappropriately and create an illusory world, where all desires come true and where they are full masters of their universe; they create a world of illusory egocentric thinking" (Vygotsky \& Luria, 1993).

I have already discussed the Vygotskian perspective on egocentrism and now would like to make another connection. While inner speech is still developing egocentrically, psychological functions of interaction remain mostly social, happening concurrently in two or more minds. A common occurrence in this social space is claiming possession of something: "This place is mine. - No, mine. - I claimed it earlier" (Vygotsky, 1982, vol. 1). What Piaget saw here as undeveloped within a line of predetermined maturation, Vygotsky designated as unmediated on a path of cultural-historical development. This unmediated desire for ownership, on the path of Western civilization, enters the relationship of dialectical unity and opposition with the key instrument of mediation - also ownership, and even though ultimately ownership of one's own will, by the nature of ownership spreading into other relationships.

Rudimentary desire for ownership which exists in many human relationships can be illustrated by the example of "Carmen's Place." Carmen's affair can also be seen as a rudimentary desire to be someone's Carmen, to be owned by someone in a life where she is otherwise independent, in charge, and happy in a relationship with José where they never tell each other what to do. In Newman's play, a possessive relationship fills the void that Carmen has been feeling and strengthens her commitment to José, who continues to completely trust her and respect her freedom. The notion of a rudimentary function, however, becomes complicated by the second meaning of the word "fantasy" in the title of the play. Indeed, how often do we meet a man without jealousy and a woman who is so much at peace with a passionate romantic affair remaining a rudimentary fantasy? This fantasy of nonpossessive love does seem like a very fitting higher-order psychological function for the cultural-historical formation where gender roles and relationships gain more and more equality. A woman's fantasy of being passionately desired could be an appropriate rudiment, filling the void and reminding us that the life we live is only one cultural and historical formation. The parallel that Newman created between the Carmen of Bizet that was written by Merimée in 1845 and his own Carmen could not have been a better illustration of this idea. 


\section{Conclusion}

This article offered a contemporary overview and development of Vygotsky's notion of rudimentary functions. It focused on the psychological rudiments mediating choice, such as flipping a coin, eidetic memory with its instances of photographic memory and déjà $v u$, self-talk, and fantasy. The format of this article did not allow inclusion of some other illustrations. For example, as one of his original three examples of rudimentary functions, Vygotsky mentioned counting on one's fingers (Vygotsky, 1983). He described this as a rudiment of a tool that initially mediated our historically holistic perception of quantities as qualities of a group, for instance as in the case of shepherds noticing an absence of one sheep in a herd, with no numerical operations involved. This genetic analysis could explain why some children have a hard time adding 2 and 2, and how they may think about what we are adding to what, because if it is sheep to wolves in a barn, the answer is certainly unknown.

Another prominent rudimentary function left outside this narrative is magical thinking (induction, transduction) as a rudiment of formal operational thought (deduction). In a genetic analysis, magical thinking showcases concrete culturalhistorical (rather than universal and supreme) nature of formal logic, supporting the significance that Vygotsky attributed to the study of rudimentary functions: "[It] should be the point of departure when unfolding historical perspective in psychological investigations. At this point, past and present are inseparably joined. In it the present is lit by the light of history, and we find ourselves in two planes: what is, and what was. It is the end of the thread that connects present and past, the highest stages of development with the initial ones" (Vygotsky, 1983).

The study of rudimentary functions is only one lens for understanding the cultural and historical roots of Vygotsky's theories. Annalisa Sannino, for example, recently chose to focus on the method of double stimulation for similar purposes, and briefly noted rudimentary functions as examples of double stimulations, stating that this was not only a method of investigation, but a principle of development (Sannino, 2015). Given the complexity of Vygotskian work, it is hard to reduce it to just one focal point, and it is my hope that the one offered in this paper was helpful.

\section{References}

Blanchfield, A., Hardy, J., De Morree, H., Staiano, W., \& Marcora, S. (2014). Talking yourself out of exhaustion: The effects of self-talk on endurance performance. Medicine \& Science in Sports \& Exercise, 46 (5), 998-1007. doi: 10.1249/MSS.0000000000000184

Chittaro, L. (2015). Assessing knowledge retention of an immersive serious game vs. a traditional education method in aviation safety. IEEE Transactions on Visualization and Computer Graphics, 21 (4), 529-538. doi: 10.1109/TVCG.2015.2391853

Cutton, D., \& Hearon, C. (2014). Self-talk functions: Portrayal of an elite power lifter. Perceptual and Motor Skills, 119 (2), 478. doi: 10.2466/29.PMS.119c25z2

Davydov, V.V. (1972). Vidy obobshcheniya v obuchenii [Types of abstraction in learning]. Moscow: Pedagogica.

Davydov, V.V. (1980). Leninskie idei o vzaimosvyazi dialektiki i psikhologii [Lenin's ideas about the interrelation between dialectics and psychology]. Voprosy psikhologii, No 2. 
Derry, J. (2013) Spinoza and free will. In Vygotsky, Philosophy and Education. Oxford: John Wiley \& Sons Ltd. doi: 10.1002/9781118368732.ch5

El'konin, D.B. (1960). Detskaya psikhologiya [Child psychology]. Moscow: Uchpedgiz.

El'konin, D.B. (1978). Psikhologiya igry [Psychology of Play]. Moscow: Pedagogy.

Herkert, H., \& Miller, K. (2015). Toward an unseen shore: Imaginative thinking in childhood grief. ProQuest Dissertations and Theses.

Holzman, L. \& Mendez, R. (Eds.) (2003). Psychological investigations: A clinician's guide to social therapy. NY: Brunner-Routledge.

Holzman, L. (2009). Vygotsky at work and play. London and NY: Routledge.

Holzman, L. (2015). The diagnostic debate: Voices from the street. Presentation at the symposium "Beyond the DSM - Current Trends in Devising New Diagnostic Alternatives." American Psychological Association Annual Convention, Toronto Ontario, August 2015.

Holzman, L. (2015). Relating to people as revolutionaries. In D. Loewenthal (Ed.), Critical psychotherapy, psychoanalysis and counselling: Implications for practice. New York: Palgrave MacMillan. doi: 10.1057/9781137460585_8

Holzman, Lois. (2016). Overweight brain. http://loisholzman.org/books/latest-installment/

Kross, E., Bruehlman-Senecal, E., Park, J., Burson, A., Dougherty, A., Shablack, H., \& Ayduk, O. (2014). Self-talk as a regulatory mechanism: How you do it matters. Journal of Personality and Social Psychology, 106(2), 304-324. doi: 10.1037/a0035173

Leontiev, A.N. (1959) Problemy razvitiya psikhiki [Problems of mental development]. Moscow: Academy of Pedagogical Sciences.

Lobman, C., \& Lundquist, Matthew. (2007). Unscripted learning: Using improv activities across the K-8 curriculum. New York: Teachers College Press.

Lobman, C., \& O’Neill, B. (2011) Play and performance. Play and Culture Studies, 11. Lanham, MD: University Press of America.

Lobman, C. (2015). Performance, theatre, and improvisation: Bringing play and development into new arenas. In J. Johnson, S. Eberle, T. Henricks, \& D. Kuschner (Eds.). Handbook of the study of play. New York: Rowman and Littlefield.

Lobman, C. \& Clark, Katelyn (2015). From the dress-up corner to the stage: Dramatic activities for early childhood classrooms. Young Children, 70(2).

Marx, K., \& Engels, F. (1957). Sochineniya [Works]. Moscow: Politizdat.

Miranda, M. (2015). Moving off the page: Tapping into young children's imagination. General Music Today, 28(2), 33-35. doi: 10.1177/1048371314557120

Newman, F. (1998) "Still on the corner" and other postmodern plays. New York: Castillo Cultural Center.

Newman, F., \& Holzman, L. (2013). Lev Vygotsky (Classic Edition): Revolutionary scientist. New York: Psychology Press.

Perone, A. (2014) Healing with(in) imaginative play. Child Life Council Bulletin, 32(3), 7.

Rogelberg, S., Justice, L., Braddy, P., Paustian-Underdahl S., Heggestad, E., Shanock, L., \& Fleenor, J. (2013). The executive mind: Leader self-talk, effectiveness and strain. Journal of Managerial Psychology, 28(2), 183-201. doi: 10.1108/02683941311300702

Sannino, A. (2015). The principle of double stimulation: A path to volitional action. Learning, Culture, and Social Interaction, 6, 1-15. doi: 10.1016/j.lcsi.2015.01.001

Vygotsky, L.S. (1925/1971). The psychology of art. Cambridge: The MIT Press.

Vygotsky, L.S. (1982). Sobranie sochinenii: Tom 1 [Collected Works: Vol. 1]. Moscow: Pedagogy.

Vygotsky, L.S. (1982). Sobranie sochinenii: Tom 2 [Collected Works: Vol. 2]. Moscow: Pedagogy.

Vygotsky, L.S. (1983). Sobranie sochinenii: Tom 3 [Collected Works: Vol. 3]. Moscow: Pedagogy.

Vygotsky, L.S. (1984). Sobranie sochinenii: Tom 6 [Collected Works: Vol. 6]. Moscow: Pedagogy. 
Vygotsky, L.S., Luria, A.R. (1993). Etyudy po istorii povedeniya. Obez"yana. Primitiv. Rebenok [Essays on the history of behavior. Monkey. Primitive man. Child.] Moscow: Pedagogy.

Williams-Bell, F., Kapralos, M., Hogue, B., Murphy, A., \& Weckman, E. (2015). Using serious games and virtual simulation for training in the fire service: A Review. Fire Technology, 51(3), 553-584. doi: 10.1007/s10694-014-0398-1

Wiley, Norbert. (2016). Inner speech and the dialogical self. Philadelphia: Temple University Press.

Zourbanos, N. (2013). The use of instructional and motivational self-talk in setting up a physical education lesson. Journal of Physical Education, Recreation \& Dance, 84(8), 54-58. doi: 10.1080/07303084.2013.827555

Original manuscript received August 23, 2016 Revised manuscript accepted September 29, 2017 First published online March 30, 2018 